\title{
Measuring of retina function using microperimetry in diabetic retinopathy
}

\author{
R. Abreu-Gonzalez ${ }^{1}$ M. Alonso-Plasencia ${ }^{1} \cdot$ M. A. Gómez-Culebras ${ }^{2}$
}

Received: 12 October 2021 / Revised: 12 October 2021 / Accepted: 15 November 2021 / Published online: 27 November 2021

(c) The Author(s), under exclusive licence to Springer-Verlag GmbH Germany, part of Springer Nature 2021

\section{Dear Editor:}

We read with interest the paper from Boned-Murillo et al. [1] regarding the structural and functional findings in patients with moderate diabetic retinopathy in which authors state that using the MAIA microperimetry system (MAIA; Centervue, Padova, Italy), the retinal sensitivity (RS) was reduced in all sectors in the diabetic retinopathy (DR) group and the central global value was $24.01 \pm 5.7 \mathrm{~dB}$ in the $\mathrm{DR}$ group and $27.31 \pm 2.7 \mathrm{~dB}$ in the control group $(p<0.001)$.

Regarding the microperimetry (MP) technology, we must have into account that with the MP it is possible to utilize different numbers of measurement points and examination grid shapes when establishing normality or disease values.

The University Hospital of La Candelaria Department of Ophthalmology in Tenerife (Spain) performed a study related to structure-function correlation using optical coherence tomography (OCT) angiography and microperimetry in diabetic retinopathy using the MP-3 system (Nidek, Aichi, Japan) in the year 2019 [2].

Boned-Murillo et al. performed a 37 points grid to test retina sensitivity in a $3 \times 3 \mathrm{~mm}$ circular area while we performed a 13 points grid to test retina sensitivity in a $4.5 \times$ $4.5 \mathrm{~mm}$ square area in order to get a wider field information with a shorter exam time. Our results showed the mean RS was decreased in the DR group $(27.68 \pm 2.71 \mathrm{~dB})$ compared to the non-diabetic group $(31.68 \pm 1.46 \mathrm{~dB})(p<0.05)$ and in the 9 studied areas $(p<0.05)$.

Interdevice comparison of retinal sensitivity has shown that there are differences between MAIA and MP-3 MP

R. Abreu-Gonzalez

rodrigoabreug@gmail.com

1 Ophthalmology Department, University Hospital of Nuestra Señora de Candelaria, Ctra. Gral. Del Rosario, 145, 38.310 Santa Cruz de Tenerife, Spain

2 Pediatric Surgery Department, University Hospital of Nuestra Señora de Candelaria, Santa Cruz de Tenerife, Spain devices related to sensitivity, luminance, and contrast sensitivity, and a standard corrector factor should be applied [3].

In our opinion, there is no a standard of the grid shape, area, and the number of points in it in the different MP manufacturers, so we cannot state a normative data for retinal sensitivity unless we specify it for a specific MP device. All measurements values in MP systems should be considered related to the MP device and grid shape and number of points we are using for.

\section{References}

1. Boned-Murillo A, Diaz-Barreda MD, Ferreras A, Bartolomé-Sesé I, Orduna-Hospital E, Montes-Rodríguez P, et al. (2021) Structural and functional findings in patients with moderate diabetic retinopathy. Graefes Arch ClinExp Ophthalmolhttps://doi.org/10. 1007/s00417-021-05277-y

2. Alonso-Plasencia M, Abreu-González R, Gómez-Culebras MA (2019 Nov) Structure-function correlation using OCT angiography and microperimetry in diabetic retinopathy. Clin Ophthalmol. 11(13):2181-2188. https://doi.org/10.2147/OPTH.S220877

3. Balasubramanian S, Uji A, Lei J, Velaga S, Nittala M, Sadda S (2018 Jan) Interdevice comparison of retinal sensitivity assessments in a healthy population: the CenterVue MAIA and the Nidek MP-3 microperimeters. Br J Ophthalmol. 102(1):109-113. https://doi.org/10.1136/bjophthalmol-2017-310258

Publisher's note Springer Nature remains neutral with regard to jurisdictional claims in published maps and institutional affiliations. 